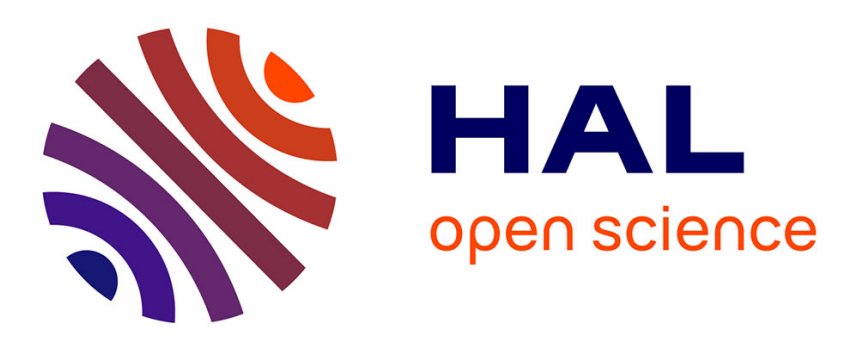

\title{
Understanding the spectrum of residential energy-saving behaviours: French evidence using disaggregated data
} Fateh Belaid, Thomas Garcia

\section{To cite this version:}

Fateh Belaid, Thomas Garcia. Understanding the spectrum of residential energy-saving behaviours: French evidence using disaggregated data . 2015. halshs-01244215

\author{
HAL Id: halshs-01244215 \\ https://shs.hal.science/halshs-01244215 \\ Preprint submitted on 15 Dec 2015
}

HAL is a multi-disciplinary open access archive for the deposit and dissemination of scientific research documents, whether they are published or not. The documents may come from teaching and research institutions in France or abroad, or from public or private research centers.
L'archive ouverte pluridisciplinaire HAL, est destinée au dépôt et à la diffusion de documents scientifiques de niveau recherche, publiés ou non, émanant des établissements d'enseignement et de recherche français ou étrangers, des laboratoires publics ou privés. 


\title{
GATE

UMR 5824

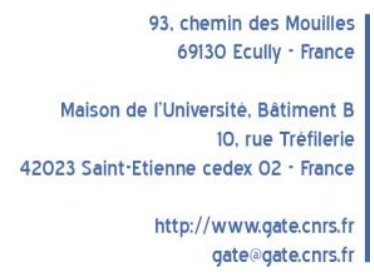

WP 1536 - December 2015

\section{Understanding the spectrum of residential energy-saving behaviours: French evidence using disaggregated data}

\author{
Fateh Belaid, Thomas Garcia
}

\begin{abstract}
:
Analysing household energy-saving behaviours is crucial to improve energy consumption predictions and energy policy making. How should we quantitatively measure them? What are their determinants? This study explores the main factors influencing residential energy-saving behaviours based on a bottom-up multivariate statistical approach using data from the recent French PHEBUS survey. Firstly, we assess energy-saving behaviours on a one-dimension scale using IRT. Secondly, we use linear regression with an innovative variable selection method via adaptive lasso to tease out the effects of both macro and micro factors on the behavioural score. The results highlight the impact of five main attributes incentivizing energysaving behaviours based on cross-variable analyses: energy price, household income, education level, age of head of household and dwelling energy performance. In addition, our results suggest that the analysis of the inverted Ushape impact of age enables the expansion of the energy consumption life cycle theory to energy-saving behaviours.
\end{abstract}

\section{Keywords:}

Energy-saving behaviours, Residential energy use, Econometric modelling, IRT, Lasso

JEL codes:

Q4, Q5, D19

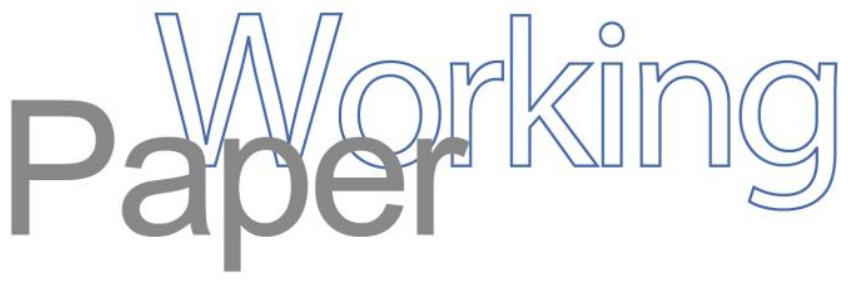




\title{
Understanding the spectrum of residential energy-saving behaviours: French evidence using disaggregated data
}

\author{
F. Belaïd ${ }^{a, *}$, T. Garcia ${ }^{a, b, * *}$ \\ ${ }^{a}$ Scientific and Technical Centre for Building, 84 avenue Jean Jaurès, 77447 Marne La Vallée, France \\ ${ }^{b}$ Université de Lyon, Lyon, F-6900\%, France ; CNRS, GATE Lyon Saint-Etienne, Ecully, F-69130, France
}

\begin{abstract}
Analysing household energy-saving behaviours is crucial to improve energy consumption predictions and energy policy making. How should we quantitatively measure them? What are their determinants? This study explores the main factors influencing residential energy-saving behaviours based on a bottom-up multivariate statistical approach using data from the recent French PHEBUS survey. Firstly, we assess energy-saving behaviours on a one-dimension scale using IRT. Secondly, we use linear regression with an innovative variable selection method via adaptive lasso to tease out the effects of both macro and micro factors on the behavioural score. The results highlight the impact of five main attributes incentivizing energy-saving behaviours based on cross-variable analyses: energy price, household income, education level, age of head of household and dwelling energy performance. In addition, our results suggest that the analysis of the inverted U-shape impact of age enables the expansion of the energy consumption life cycle theory to energy-saving behaviours.
\end{abstract}

Keywords: Energy-saving behaviours, Residential energy use, Econometric modelling, IRT, Lasso JEL: Q4, Q5, D19

\section{Introduction}

The building sector accounts for one of the major share of total primary energy consumption in most countries. Today, it is responsible for more than one-fifth of global energy consumption of delivered energy and as much as one-tenth of global greenhouse gas emissions, both in developed and developing countries. The amount of domestic energy used can vary widely within and across regions and countries. Various factors influence the ways in which energy is consumed by households, such as energy prices, household and dwelling characteristics, access to delivered energy, climate, home appliances types and effi-

\footnotetext{
*Principal corresponding author

** Corresponding author

Email addresses: Fateh.BELAID@cstb.fr

(F. Belaïd), GARCIA@gate.cnrs.fr (T. Garcia)
}

ciencies, energy sources and energy-related policies. Concerning the French case, the building sector is relatively intensive in energy as it was responsible for $30 \%$ of the total energy consumed and $20 \%$ of the $\mathrm{CO}_{2}$ emissions produced in 2014 . It is projected that with current policy settings residential energy demand will continue to grow and World residential energy consumption will increase by $57 \%$ from 2010 to 2040 , mainly as a result of growing residential demand in the nonOECD countries (IEO, 2013). The residential sector has the largest potential for delivering longterm, significant and cost-effective reduction of greenhouse gas emissions. Therefore, making the housing stock as energy efficient as possible would bring multiple benefits to both the economy and the society.

While the impact of behaviours on energy consumption is fairly well apprehended, the factors 
influencing energy behaviours have not so far gotten much attention. It is essential to accurately assess energy behaviours to better define public policies' targets. Besides promoting energy efficient technologies and new energy resources development, changing occupants behaviour appears as a promising way of fostering energy efficiency in housings. In this context, our main objective is to provide further insight into how to improve the effectiveness and efficiency of energy policy making promoting more sustainable consumption patterns through a better identification of households involved in energy intensive behaviours.

For the lack of availability of disaggregated data on household energy usages, the majority of residential energy studies in this last decade have been dominated by the technical and physical research. More precisely, very few studies have focused on socio-economic energy-saving behaviours determinants (Sardianou, 2007; Sanquist et al., 2012; Yue et al., 2013). To our knowledge, the present paper is the first to use microlevel data to investigate the impact of household characteristics, climate, physical and energy performance characteristics on domestic energysaving behaviour. It is based on PHEBUS ${ }^{1}$, a new data base containing information on the dwelling characteristics, the occupant's energy behaviours and their socio-demographic features combined with energy performance certificate (EPC). Starting by evaluating energy-saving behaviours on a one-dimension scale using Item Response Theory (IRT), we associate multivariate regression with adaptive lasso variable selection to identify the factors influencing energy-saving behaviours. Our results aim to contribute improving the understanding of the energy behaviours' black box.

The remainder of this paper is organised as follows: Section 2 gives a brief theoretical background on energy behaviours. Section 3 presents the conceptual framework and research hypotheses. Section 4 describes the data and the modelling approach. We report our empirical findings

\footnotetext{
${ }^{1}$ PHEBUS is a French acronym corresponding to: Housing performances, equipment, needs, and usages of energy.
}

and discuss their implications in Section 5. Based on the results of the model, we draw conclusions and provide some policy implications in Section 6 .

\section{Theoretical background}

Domestic energy consumption is a complex issue closely linked to the multitude of inter-related factors including direct factors such as technical attributes of the buildings, household characteristics and behaviour, energy systems, climate, equipment, but also indirect drivers such as fuel prices and inflation considered by macroeconomists (Summerfield et al., 2010). Currently there is a lack of models or studies that include all of these factors. Since the late 1970s, in the aftermath of the oil crisis, concerns regarding residential energy use and conservation triggered a first wave of studies. Studies have varied in terms of approach (conceptual, methodological, and/or unit of analysis) and purpose (estimation, energy reduction, and/or energy conservation) (Valenzuela et al., 2014). This theme was particularly stimulated both by the increasing awareness of global warming, climate change, fossil fuel depletion and rising oil prices in recent years.

Broadly, as described by Swan and Ugursal (2009), there are two fundamental methods adopted to model and analyse various aspects of residential energy consumption: top-down and bottom-up approaches. Top-down models work at an aggregated level; usually using time series models to investigate inter-relationships between the energy sector and the economy. Bottom-up models are based on disaggregated views, they use high resolution data to estimate energy consumption and $\mathrm{CO}_{2}$ emissions. Two classes of models can be identified within bottom-up models: engineering and statistical models. The approach proposed in this study corresponds to a bottom-up statistical model analysing the effects on household energy behaviours by using high resolution data containing technical, socio-demographic and behavioural data on households.

Over the last few years, empirical studies on residential energy consumption have received considerable attention. For reasons of non- 
availability of disaggregated data, most of these studies use aggregated time series data, and only a few micro studies use the available householdlevel data (Zhou and Teng, 2013). Furthermore, many of the current studies on energy consumption in the residential buildings and debates regarding energy efficiency in the housing stock focus on the physical and technical determinants of energy consumption, neglecting the role of the economic behaviours of resident households (Brounen et al., 2012). Previous studies in the USA and the Netherlands have determined that building characteristics explain from only $40 \%$ to $54 \%$ of the variation in energy use (Guerra-Santin and Itard, 2010; Sonderegger, 1978). Summerfield et al. (2010) stated that energy use in U.K. households may vary by up to three times in properties with similar physical attributes. Energy behaviours thus represent a significant potential for the increase of end-use energy efficiency in dwellings.

Conscious of the behaviours' large impact, some researches emphasise on the importance of analysing the factors influencing energy conservation behaviours (Dwyer et al., 1993; Abrahamse et al., 2005; Darby et al., 2006; Allcott, 2011; Ehrhardt-Martinez et al., 2010; Yue et al., 2013). Most of these studies tackle the energy behaviours from a social sciences point of view and especially using environmental psychology (Lopes et al., 2012). Recent literature on household energy use and energy-saving behaviours recognises that domestic energy use depends on factors such as energy price, climate, and building and household characteristics but also on the householders' energy-saving behaviours (Barr et al., 2005; Branco et al., 2004; Lindén et al., 2006; Fabi et al., 2012; Mizobuchi and Takeuchi, 2013). One of the most relevant study on residential energy behaviours is due to Steg and Vlek (2009). The authors reviewed the contribution and the potential of environmental psychology for understanding and promoting pro-environmental behaviours.

Lopes et al. (2012) proposed a review of recent literature on energy behaviours exploring peer-reviewed publications in the field of energy behaviours, domestic end-use energy behaviours, and modelling behaviours approach. This study concludes that energy behaviours are highly complex, shaped by many factors both individual and contextual. Due to this complexity, they are usually studied using fragmented and disciplinary studies from a wide range of disciplinary areas such as sociology, psychology, economics and engineering. This section gives a brief overview of relevant studies that focus on the factors influencing households energy behaviours. Sardianou (2007) developed an empirical model (latent trait model OLS regression) to investigate the main determinants of household energy conservation patterns in Greece using cross-section data based on an extensive survey of 586 Greek households. The study uses four subsets of variables: economic factors (private monthly income, electricity expenditures), demographic variables (age, sex and educational level of the respondent, marital status and family size), dwellings characteristics (homeownership, house type, number of rooms and size in $\mathrm{m}^{2}$ ), information diffusion and attitudinal variables (individuals belief about their contribution to environmental problems). The results show that socio-economic variables such as consumers income and family size are suitable to explain differences in energy conservation preferences. In addition, the results suggest that electricity expenditures and age of the respondent are negatively associated with the number of energy conserving actions that a consumer is willing to adopt. Sanquist et al. (2012) investigated the role of lifestyle dimensions of residential electricity consumption using multivariate statistical approach namely factor analysis and multiple regression analysis. They used variables from the 2005 U.S. Residential Energy Consumption Survey (RECS). Their research shows that five lifestyle factors account for more than $40 \%$ of the variance in electricity consumption and income adds negligibly to predictive power (contributes $1 \%$ unique variance to the models).

Recently, Yue et al. (2013) used a statistical analysis (descriptive statistical analysis, bivariate correlation, multiple and hierarchical linear regression) to explore factors influencing energy-saving behaviours of urban households by 
analysing the differences in households willingness to adopt three types of energy-saving behaviours in Jiangsu Province (China) and four dimensions of influencing factors: socio-demographics, energy-saving awareness, behavioural ability, and institutional factors. Their study is based on an internet survey that was sent out to 638 households. The results indicate that sociodemographic characteristics, including age, gender, income level, household structure, and educational background, are the most important factors influencing energy-saving behaviours.

\section{Conceptual framework and research hy- potheses}

First of all, the concept of energy behaviours need to be tackled on a semantic point of view as the delimitation between behaviours and technical attributes of the building can be blurred. In its wider definition, this term is used in the literature to define the occupants' influence on the housing as well as general thinking and attitudes towards energy-saving (Sardianou, 2007). It can gather very different aspects such as the equipment level, some characteristics of the housing directly related to energy-saving theoretically modifiable by the occupants, ideological position on energy-saving or proselytism level of these opinions. Some of these characteristics make sense in a dynamic framework (technological improvements) when some others are to be analysed in a static one (given a technological level how do someone behave). Furthermore, it includes actions - what I do - as well as beliefs on these actions - what I think I do. In line with Lopes et al. (2012), we choose to refer to energy-saving behaviours to express habits that are incorporated in the routine and repeated automatically. The fact that they are recurrent actions excludes purchasing behaviours that are discrete actions. They answer the question: to what extent is someone an energy-saver given the possibilities offered by his dwelling?

Adopting this conservative definition of energy-saving behaviours can appear as ambitious because establishing a link between technology in- dependent behaviours and characteristics is difficult. However, it enables us to best tackle the intrinsic meaning of behaviours and our conclusions not to be biased by the fact that all households do not have the same access to improvements (the housing occupation status playing, for example, a key role) and that they have moved in unequally equipped housings.

After their identification, energy-saving behaviours need to be accurately measured. Our data-base contains either self-reported behaviours or self-reported beliefs on behaviours. While actual behaviours and beliefs can be different because of a judgement bias, self-reports appear as more homogeneous. This is why we have included both kinds of information on energy-saving behaviours.

Based on the literature and on micro-economic theoretical insights, we aim to test the following set of hypotheses.

H 1. Energy-saving behaviours are positively affected by the energy price.

H 2. Energy-saving behaviours are negatively affected by the households' revenue.

$\mathbf{H}$ 3. Households living in highly energyconsuming buildings behave in a more energysaving manner.

H 4. Energy-saving behaviours are positively affected by the households' education level.

H 5. Energy-saving behaviours intensity follows an inverted $U$-shape curve with the age.

Hypothesis 1 is a price effect, Hypothesis 2 a revenue effect and Hypothesis 3 a cost per unit of service effect. Hypothesis 4 is motivated by the alignment of environmental behaviours and education level (Hines et al., 1987) while Hypothesis 5 matches the life-cycle theory of energy consumption (Fritzsche, 1981). 


\section{Data and modelling approach}

\subsection{Data}

This research is based on the 2014 PHEBUS $^{2}$ new national household energy survey conducted by the Department of Observations and Statistics (SOeS) depending on the French Ministry of Ecology and Sustainable Development. In this study, we focused on 2,356 households in housing units statistically selected to represent 27 million housings in France. PHEBUS variables cover the household socio-demographic characteristics, the physical characteristics of the dwellings, appliance information, fuel types and related consumption. Furthermore, it contains data on housing energy performances coming from diagnosis lead by certified professionals.

\subsection{Variables characterising energy-saving behaviours}

Consistently with the previous definition of energy-saving behaviours, we have selected eight ordinal variables of interest in the PHEBUS database with their modalities ranked from the more energy-intensive to the more energy-saving behaviour. Six of them are binary variables. Concerning heating actions, we take into account selfimposed restrictions during winter (HR) as well as decreasing periodically the heating temperature in the night space (DSN) and elsewhere in the dwelling (DD). Beliefs regarding heating (HB), electricity (EB) and hot water (HWB) usages are evaluated by the preference between saving and comfort. The last actions in the scope of this paper take three modalities. The frequency of window opening per day during heating periods (WO) is considered either equal to more or less than 15 minutes a day by opposition to occasional opening. Regarding the heating temperature (HT), between $19{ }^{\circ} \mathrm{C}$ and $20^{\circ} \mathrm{C}$ is considered

\footnotetext{
${ }^{2}$ Access to data can be gained from the Service of Observations and Statistics (SOeS) attached to the French Ministry of ecology, Sustainable Development and Ecology, subject to the prior agreement of the Committee on Statistical Confidentiality.
}

as the average ${ }^{3}$, a warmer heating or a colder one are defined accordingly.

The variables characterising the energysavings are very oriented towards non-intensive heating behaviours as six out of eight variables are related to heating behaviours. In comparison, the European residential building as $57 \%$ of the total final energy consumption is used for space heating, $25 \%$ for domestic hot water and $11 \%$ for electricity (Chwieduk, 2003).

To have a clear idea on the composition of the selected behaviour variables, we focus on their distribution (Table 1) and on their correlation factors (Figure 1). The observation numbers reveal the almost completeness of our database as no variables are missing more than $3 \%$ of answers.

All correlation coefficients are positive, supporting a global coherence in selected energysaving behaviours. However, window opening appears to be singular, as it is not significantly (at a $5 \%$ level) correlated with other variables than the heating temperature. The highest covariance is between the two temperature modulation behaviours as they are highly correlated with a similar characteristic: the fact of being equipped of a temperature modulator. Finally, we note that there are three times as many households overheating their dwelling than under-heating it which is in line with the fact that only one fifth of all households reports to apply heating restrictions. Regarding beliefs, households tend to prefer heating comfort over electricity comfort. The three kinds of belief are highly correlated (coefficients between 0.4 and 0.5). Modulating the temperature in the night-space is independent from ones' beliefs concerning hot water and electricity but, as expected, significantly correlated with heating beliefs.

\footnotetext{
${ }^{3}$ The recommendation of the "Agence de l'environnement et de la maîtrise de l'énergie" (ADEME) is to heat at $19^{\circ} \mathrm{C}$ which appears as a low reference level. We have added households heating their dwelling at $20^{\circ} \mathrm{C}$ to the reference class to have a more balanced ranking.
} 


\begin{tabular}{ccccccc}
\hline \hline & & & & \multicolumn{3}{c}{ Density } \\
\cline { 5 - 7 } Actions & & & & & & \\
$W O$ & 2,356 & 1.584 & 0.720 & $55 \%$ & $31 \%$ & $14 \%$ \\
$H T$ & 2,333 & 1.817 & 0.616 & $30 \%$ & $59 \%$ & $11 \%$ \\
$D D$ & 2,356 & 1.447 & 0.497 & $55 \%$ & $45 \%$ & \\
$D S N$ & 2,356 & 1.498 & 0.500 & $50 \%$ & $50 \%$ & \\
$H R$ & 2,356 & 1.219 & 0.414 & $78 \%$ & $22 \%$ & \\
Beliefs & & & & & & \\
$H B$ & 2,306 & 1.415 & 0.493 & $59 \%$ & $41 \%$ & \\
$E B$ & 2,328 & 1.579 & 0.494 & $42 \%$ & $58 \%$ & \\
$H W B$ & 2,334 & 1.446 & 0.497 & $55 \%$ & $45 \%$ & \\
\hline \hline
\end{tabular}

Table 1: Statistical description of energy behaviours

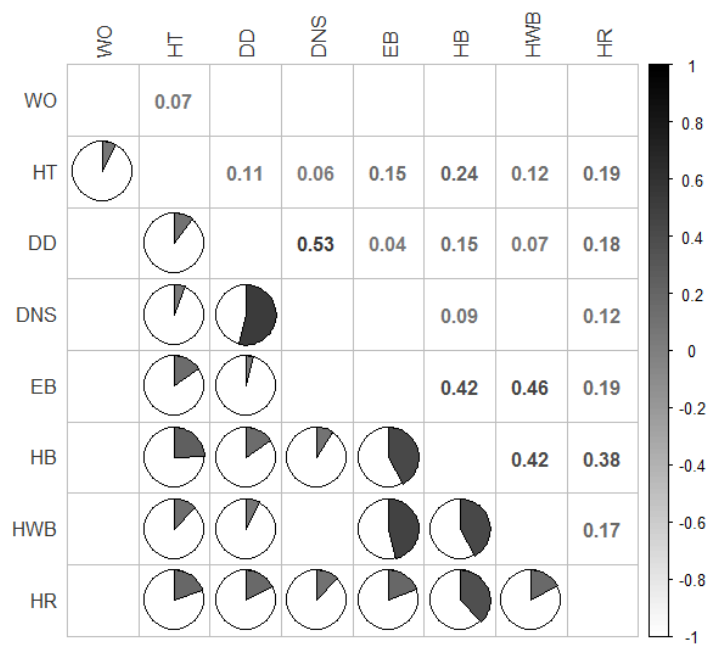

Figure 1: Covariance matrix of energy behaviour variables

Reading note: in the lowest part of the diagram is represented the intensity of the correlation using pies filled on the right side for positive correlations and on the left side for negative ones. The upper part gives the numeric values. Only correlations between variables significantly correlated at a $5 \%$ level are given.

\subsection{Variables explaining energy-saving be- haviours}

In order to correctly assess the potential factors influencing energy-saving behaviours, we need to evaluate these behaviours not only regarding individuals distinctiveness but also by analysing what is surrounding them. Obviously, individual features such as age, gender, or social background are expected to play a key role in explaining the energy-saving behaviours. However, households' behaviours are difficult to understand without apprehending the characteristics of what is surrounding them. At the least detailed level, geographic considerations such as the urban structure or the climate quality are to be studied. Regarding the physical discriminating factors two scopes can be distinguished, on the one hand the outside of the construction - the building - and on the other hand the inside - the indoor dwelling. The first set, preceding the second one on a macro to micro scale, includes the EPC or the proximity to other housings, while the second one is largely dedicated to equipment including heating equipment's characteristics.

The composition of the different levels of analysis are summarised in Figure 2.

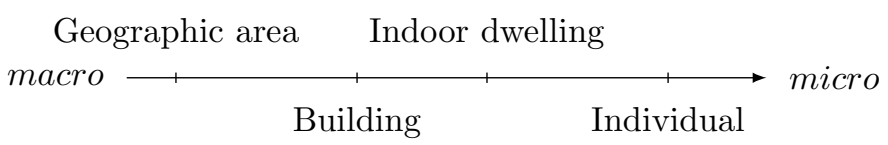

Figure 2: Representation of the different levels of analysis on a macro to micro scale

Table 2 and Table 3 give an extensive vision of respectively the quantitative and categorical characteristics in the scope of the study. Regarding the geographic area, the temperature index used is the Heating Degree Day (HDD) index. Based on the minimal and maximal daily outside temperature, it provides a simple metric for quantifying the amount of heating that buildings, in a particular location, need. The higher the HDD is, the more heating is needed. We have separated Paris conurbation from the other urban areas of more than 200,000 inhabitants to be able to take into account the specific role played by 
Paris in the French system. The EPC is based on both outside and inside dwelling characteristics. It is highly related with the construction year, the isolation performance or the roofing and, for part of the residential buildings, the diagnosis has been based on a collective approach. Therefore, we have chosen to include it among the building characteristics. The delimitation of the indoor dwelling group is closely related to our definition of energy-saving behaviours. We have excluded from the behavioural set all characteristics related to equipment or dwelling improvement, however they can be use-full in explaining these behaviours. For the equipment intensity, we have ranked households in four classes according to the number of small electric equipment as oven, washing machine, computers or television sets owned. As for house refurbishment, it indicates if works have been undertaken in the dwelling in the past few years. Finally, the energy price is computed ex-post based on total energy spending and energy consumption which explains its high variance. Individual characteristics correspond to the person self-determined as being the reference person for the household except for the earnings. This choice was driven by the necessity to have a bijection between individuals' and households' characteristics. Males being more than twice as represented as females, it reveals the fact that they have a higher propensity to self-declare as reference person for the household. Nationality splits the sample between French-born individuals and others. Earnings are based on declarations and correspond to monthly income for the whole household. We have chosen to split the age variable in four classes to be able to assess Hypothesis 4. While the current professional status is given by occupation, the socio-occupational categories correspond to either former or actual occupation in order to control for a hypothetical time-availability effect.

\begin{tabular}{lcccc}
\hline \hline & Unit & $\mathrm{N}$ & Mean & St. Dev. \\
\hline $\begin{array}{l}\text { Geographic area } \\
\text { Temperature index }\end{array}$ & ${ }^{\circ} \mathrm{C} \times$ day & 2,168 & 2,490 & 386.605 \\
Indoor dwelling & & & & \\
$\quad$ Size & $\mathrm{m}^{2}$ & 2,352 & 105.281 & 45.021 \\
$\quad$ Energy price & $€ / \mathrm{kWh}$ & 2,356 & 0.109 & 0.035 \\
Individual & & & & \\
$\quad$ Number of people & $\mathrm{nbr}$ & 2,356 & 2.543 & 1.323 \\
Earnings & $€ / \mathrm{month}$ & 2,203 & 3,392 & 6,531 \\
\hline \hline
\end{tabular}

Table 2: Statistic description of quantitative variables

\subsection{Modelling approach}

An accurate measurement of energy-saving behaviours' need to overcome two features of ecological behaviours: i) the inconsistency from one behaviour to another, ii) the unequal difficulty of all behaviours (Kaiser, 1998).

Influenced by social and cultural conditions as well as by the power of habits, individuals may behave ecologically in one domain but not in another (Pickett et al., 1993). In order to draw robust conclusions on a global energy-saving scale, it is important to smooth these inconsistencies by establishing an agglomerate measurement. For this purpose, the unequal difficulty of each behaviour can be an obstacle. As an example, self-imposed heating restrictions are more constraining than heating modulation while out of the dwelling. The IRT gives an adequate solution as it enables us to compare each household on a unique energysaving scale which takes into account the respective difficulty of each behaviour. IRT is a modelbased approach establishing a latent ability characteristic from answers to a questionnaire. As the set of energy-saving behaviours is composed of ordinal polytomous data, the underlying modelisation used is the Graded Response Model (GRM) introduced by Samejima (1969). Considering $x_{i m}$ the ordinal manifest variable, $z_{m}$ the latent ability, $\alpha_{i}$ the discrimination parameter and $\beta_{i k}$ the extremity parameters. GRM postulates that the probability of the $m^{\text {th }}$ subject to endorse the $k^{\text {th }}$ response of the $i^{\text {th }}$ item is expressed using a logistic function: 


$$
\begin{gathered}
\mathbb{P}\left(x_{i m} \leq k \mid z_{m}\right)=\frac{\exp \left(\alpha_{i}\left(z_{m}-\beta_{i k}\right)\right)}{1+\exp \left(\alpha_{i}\left(z_{m}-\beta_{i k}\right)\right)} \\
\mathbb{P}\left(x_{i m}=k \mid z_{m}\right)=f\left(w_{i k}\right)-f\left(w_{i, k+1}\right)
\end{gathered}
$$

where $w_{i k}=\alpha_{i}\left(z_{m}-\beta_{i k}\right), f(w)=\frac{\exp (w)}{1+\exp (w)}$,

$$
\text { and } \beta_{1}<\beta_{2}<\ldots<\beta_{K}
$$

Then, we estimate the model using the MMLE maximization method (Baker and Kim, 2004) and the households' latent abilities with the maximum aposteriori approach.

In order to evaluate the impact of each characteristic on the latent ability level we use a three steps approach. i) we regress the previously described explanatory variables on the latent ability vector. We use a multivariate linear regression specifying the score and the categorical variables in level and the explicative quantitative variables in logarithm (exception made of the number of people). ii) to increase the interpretability of our model, we implement an adaptive lasso method (ALASSO) - an innovative variable selection method for regression (Zou, 2006), iii) we run the final regression with the selected explanatory variables.

Besides prediction accuracy another important criterion of robustness and goodness of the fitted underlying model is sparsity or parsimony. Variable selection might be an attempt to identify the best subset of important predictors among many variables to include in a model. This selection aims to improve the estimation accuracy and enhance the model interpretability with parsimonious representation. It is particularly important to high dimensional regression modeling. ALASSO is one among numerous subset selection automated procedure based either on sequential multi-variable evaluations or parameters shrinkage. It has several features that distinguish it from other traditional techniques of variables selection. The chief advantages of adaptive lasso over other methods (Zou, 2006) is:

- The ALASSO enjoys the oracle properties in the sense of Fan et al. (2004) by utilizing the adaptively weighted $l_{1}$-penalty even when the number of covariates is much larger than the sample size.

- The ALASSO shrinkage leads to a nearminimax optimal estimator even in the case of heteroskedastic data (Caner and Fan, 2011).

- The ALASSO is computationally efficient compared to the smoothly clipped absolute deviation and bridge methods, i.e., ALASSO estimate is a convex optimization problem.

ALASSO method shown to be both consistent in variable selection and asymptotically normal in coefficient estimation. However, ALASSO not only helps to improve the prediction accuracy when dealing with multicolinearity data, but also carries several properties such as interpretability and numerical stability.

Regarding the other methods some main drawbacks have been identified arguing in favour of the superiority of the ALASSO. As an example, stepwise methods suffer from high variability regarding the order of selection or data changes (Breiman, 1995) while ridge regressions does not enable to shrink coefficients to zero. Moreover, Fan and Li (2001) show that for large coefficients the lasso shrinkage (Tibshirani, 1996) produces bias. Formally, the ALASSO is based on the following minimisation problem. Considering $\lambda$ the amount of shrinkage, $y$ the vector of responses and $X=\left(x_{1}, \ldots, x_{p}\right)$ the matrix composed of the $p$ linearly independent predictor vectors, the adaptive lasso solves the OLS regression problem adding a weighted $l_{1}$-norm penalty on the coefficients:

$$
\begin{gathered}
\hat{\beta}(\text { adaptive lasso })= \\
\underset{\beta}{\arg \min }|| y-\sum_{i=1}^{p} x_{i} \beta_{i} \|^{2}+\lambda \sum_{i=1}^{p} \hat{w}_{i}\left|\beta_{i}\right| \\
\text { where } \hat{w}=1 /|\hat{\beta}|
\end{gathered}
$$

Then, are selected for the final regression only the non-zero coefficient variables. 


\begin{tabular}{|c|c|c|}
\hline Variable & Modality & $\mathrm{N}$ \\
\hline \multicolumn{3}{|l|}{ Geographic area } \\
\hline \multirow{5}{*}{ Urban structure } & Paris conurbation & 319 \\
\hline & Rural commune & 595 \\
\hline & From 2,000 to 20,000 inhabitants & 434 \\
\hline & From 20,000 to 200,000 inhabitants & 428 \\
\hline & More than 200,000 inhabitants & 580 \\
\hline \multicolumn{3}{|l|}{ Building } \\
\hline \multirow[t]{3}{*}{ Proximity to other households } & Shared building & 663 \\
\hline & Isolated individual house & 1189 \\
\hline & Semi-detached house & 504 \\
\hline \multirow[t]{4}{*}{$\mathrm{EPC}$} & $A-B-C$ & 369 \\
\hline & $D$ & 633 \\
\hline & $E$ & 691 \\
\hline & $F-G$ & 635 \\
\hline \multicolumn{3}{|l|}{ Indoor dwelling } \\
\hline \multirow[t]{3}{*}{ Heating system } & Shared central & 226 \\
\hline & Individual central & 1809 \\
\hline & Other & 321 \\
\hline \multirow[t]{3}{*}{ Heating energy } & Electricity & 816 \\
\hline & Gas & 862 \\
\hline & Other & 678 \\
\hline \multirow[t]{2}{*}{ House refurbishment } & Yes & 1176 \\
\hline & No & 1180 \\
\hline \multirow[t]{4}{*}{ Equipment intensity } & Very low & 588 \\
\hline & Low & 707 \\
\hline & High & 560 \\
\hline & Very high & 501 \\
\hline \multicolumn{3}{|l|}{ Individual } \\
\hline \multirow[t]{4}{*}{ Age } & Less than 44 & 614 \\
\hline & From 45 to 56 & 604 \\
\hline & From 57 to 66 & 565 \\
\hline & More than 67 & 573 \\
\hline \multirow[t]{2}{*}{ Dwelling occupancy status } & Owner & 1751 \\
\hline & Tenant & 605 \\
\hline \multirow[t]{2}{*}{ Social housing } & No & 2100 \\
\hline & Yes & 256 \\
\hline \multirow[t]{7}{*}{ Socio-occupational category } & Top managerial and intellectual profession & 427 \\
\hline & Employee & 536 \\
\hline & Worker & 612 \\
\hline & Intermediate profession & 539 \\
\hline & Artisan, shopkeepers, heads of businesses & 49 \\
\hline & Farmer & 40 \\
\hline & Other & 40 \\
\hline \multirow[t]{4}{*}{ Professional occupation } & Employed & 1217 \\
\hline & Unemployed & 105 \\
\hline & Retired & 916 \\
\hline & Other & 118 \\
\hline \multirow[t]{2}{*}{ Gender } & Female & 738 \\
\hline & Male & 1617 \\
\hline \multirow[t]{2}{*}{ Nationality } & French & 2144 \\
\hline & Other & 212 \\
\hline
\end{tabular}

Table 3: Statistic description of categorical variables 


\section{Results}

\subsection{Latent ability}

We first estimate the item difficulty, i.e. the probability of exhibiting each behaviour composing the score $\left(\mathbb{P}\left(x_{i m}=k\right)\right)$ as function of the ability level (Figure 3$)$. In line with the relative independence between the window opening observed in Subsection 4.2 and the other energy-saving behaviours, we notice that this behaviour has only a low influence on the latent ability. Apart from WO, for an increasing level of ability, one household has strictly increasing odds to behave in a more energy-saving way. The point at which one modality becomes more likely than another is related to the proportion of households involved in each one of them. For example, only households with an ability greater than three are more likely to heat their housing at a temperature lower than $19{ }^{\circ} \mathrm{C}$ as only $11 \%$ of the sample behave in such a manner. The sharpness of the curves is function of the correlation with other variables. In the set of ability determinant variables, DNS is the only one not correlated with all other variables, unsurprisingly it is for this variable that we note the smaller influence of a deviation from the point of equal likelihood. The heating belief is strongly correlated with the other behaviours, therefore it has the highest first derivative (in absolute value) in a neighbourhood of the point of equal likelihood. The latent ability vector obtained is statistically described in Table A.5, its kernel density has a three-bump shape (Figure A.4).

\subsection{Hypotheses testing and discussion}

The hypotheses testing is discussed based on the results of the linear multivariate regression with only the variables selected by the adaptive lasso (Table 4). The adaptive lasso shrinkage pattern is described in Appendix B.

Firstly, we observe a price effect as the energy price is one of the three significant effects at a $1 \%$ level, confirming Hypothesis 1 . The more expensive energy intensive behaviours are, the less households consume them. Having a shared central heating system also a highly significant effect on the latent ability ( $\mathrm{p}$-value $<0.01)$ which is negative. It strengthens the previous result as a shared central heating system often goes with a miss-information upon pooled energy expenses. It denotes that not only the price is important but also the feed-backs on this price, which has been identified as one of the most effective way of action of energy-efficiency policies (Lopes et al., 2012; Mizobuchi and Takeuchi, 2013). It is also related with the fact that when possessing a shared heating system individuals have less possibilities to regulate the temperature and may thus have to engage in energy-wasting behaviours such as opening windows during a heating period to control the inside temperature. We fail to demonstrate a revenue effect (Hypothesis 2). Energysaving behaviours do not seem to be normal goods as their demand is independent from the revenue level. It can be explained by the fact that households do not feel any gain in over-consuming energy. Households with good energy-behaviours will not change their habits due to a higher income. The impact of revenue and price on behaviours is to be put in relation with their effect on energy consumption. It has been in the scope of several studies such as Labandeira et al. (2005) regarding prices; Cayla et al. (2010) or Cayla et al. (2011) regarding revenues; and Parti and Parti (1980), Dubin and McFadden (1984), Baker et al. (1989), Nesbakken (2001), Bernard et al. (1996) or Branch (1993) for cross analysis. As reviewed by Risch and Salmon (2013), the energy price elasticity estimations vary from -0.2 to -1.14 while the energy income elasticity is estimated to be lower, ranging between 0.01 and 0.13 . Therefore our findings on price and revenue effect on energysaving behaviours are consistent with the important difference between energy price and energy income elasticities.

Hypothesis 3 is largely confirmed by our results as most building characteristics related to high energy consumption are also linked with more energy-saving behaviours. Households living in shared buildings have lower latent abilities than those living in isolated or semi-detached houses. In multi-households dwellings, there are synergies between the different heating actions of all households occupying the same building. It 


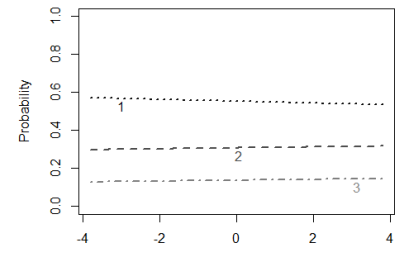

Ability

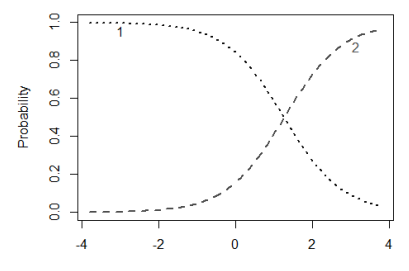

Ability
$H R$

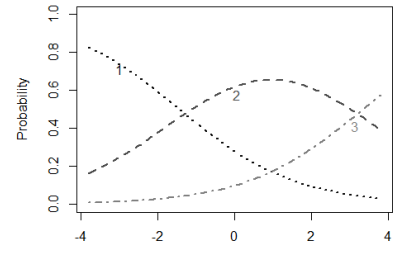

Ability

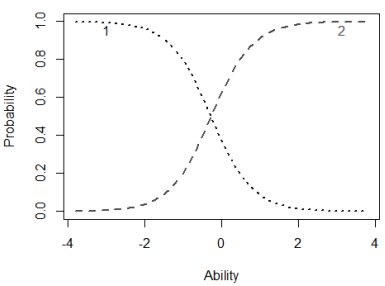

$E B$

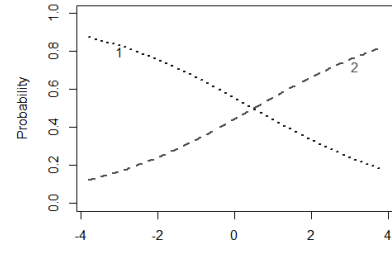

Ability

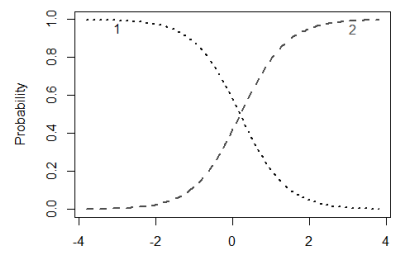

$H W B$

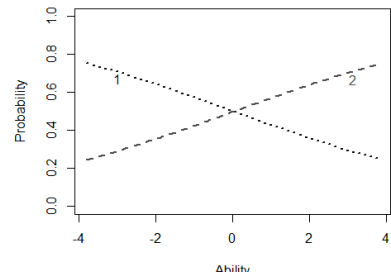

$D N S$

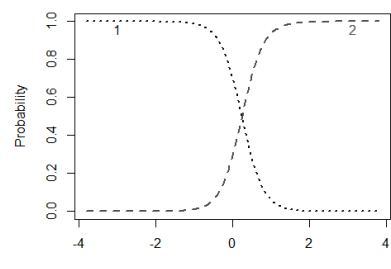

Ability

Figure 3: Item difficulty estimation

is easier for the occupants to be well heated and they have less to invest to find energy-comfort. The effect of EPC is in line with this statement, households living in dwellings ranked at the bottom of the energy-performance scale are the ones with the better energy behaviours. In F or G EPC ranked dwellings, it is important to modulate the heating temperature while away because of the heat loss or to favour economy over comfort as the price of comfort can be really expensive. Additionally, the temperature index is the last clue regarding the veracity of Hypothesis 3 as the colder the outside temperature is, the more households show energy-saving behaviours. Once again, the impact of these behaviours is higher in colder regions as the cost of having a high heating temperature or to seek for heating comfort is higher. The size effect is the only result not supporting $\mathrm{Hy}$ pothesis 3 as in a larger dwelling, energy-saving behaviours have more impact. However, it could lays within the fact that, in a smaller dwelling, an energy-saving way of life may be easier to undertake and less time consuming. To sum up, a household living in a building having a propensity to consume a high amount of energy behaves as energy-savers because of an important leverage effect of each of their actions on the energy consumption level. The confirmation of Hypothesis 3 is to be analysed in the light of the rebound effect literature. The rebound effect theory enables to assess energy-behaviours based on a comparison between expected consumption predicted by engineers and the actual consumption. When a household moves into a more efficient dwelling, the cost per unit of service of the equipment falls. Therefore, households adapt to a more energyintensive way of behaving, decreasing the potential impact of the improved performances of their new dwelling (Berkhout et al., 2000). Based on a survey from Greening et al. (2000), the rebound effect is expected to range from $10 \%$ to $30 \%$ regarding space heating and $10 \%$ to $40 \%$ in water heating ${ }^{4}$.

Even if we do not observe the education level a cross-analyses of the variables related to the profession gives results that cannot support Hypothesis 4. In opposition to highly educated socioprofessional categories - mainly top managerial and intellectual professions -, socio-professional categories with an average level of education employees, workers, or intermediate professions exhibit more energy-saving behaviours. In addition, the relatively low educated farmers do not have worst behaviours. It is in line, with the neg-

\footnotetext{
${ }^{4} \mathrm{~A}$ rebound effect of $\mathrm{X} \%$ means that $\mathrm{X} \%$ of the potential gain in consumption vanishes in behaviour adaptation.
} 
ative effect of being employed compared to being unemployed or to have a professional occupation status not mentioned ${ }^{5}$ as a high educational level and intellectual background is positively correlated with the fact of being employed. This result cannot be interpreted only as a time availability effect otherwise retired people should behave more like energy-savers revealing that a social class mechanism could be in action. Sociooccupational categories correspond to different social classes which directly influence social status (Bourdieu, 1984). A higher social status may incentivise more energy consuming behaviours through a preference for comfort over savings or a tendency not to stand for heating restrictions. The non-validation of Hypothesis 4 establishes a gap with the environmental literature as environmental behaviours are known to be positively correlated with the education level (Hines et al., 1987). Households with a higher education level have been found to be more receptive to environmental friendly ideas or to be better informed about issues related to global warming, exhibiting better behaviours. However when it comes to energy-saving behaviours this impact is overcome by what we have interpreted as being a social status effect.

The inverted U-shape distribution of latent ability as a function of the age (Hypothesis 5) is supported by the results as one of the middle age classes is more energy-saver. The explanation of these results stands in the composition of the under 45 years old class. Only $8 \%$ of individuals belonging to this class are under 28 which is the average age at first childbearing in France ${ }^{6}$. Therefore, it is mainly composed of parents with young children $^{7}$. To have a young child in the dwelling may explain the fact that individuals do not be-

\footnotetext{
${ }^{5}$ Individual with a occupation status not mentioned are either student, housewife/husband or having another kind of inactivity

${ }^{6}$ Data from INSEE (French National Institute of Statistics and Economic Studies).

${ }^{7} 78 \%$ of all households with a child under 10 years old are in the less than 45 years old class and $56 \%$ of the previously mentioned class have a child under 10 years old.
}

have as energy-savers and choose to favour comfort of their child against savings. Once their children are older, parents can shift their behaviours to more environmental ones. Finally, when getting older people tend to seek for more energy comfort, but this time for themselves. In addition, the age has been shown to have a negative impact on environmental behaviours which strengthens the difference in behaviour between the middleage class and the oldest ones. This effect can be explained by a higher behavioural inertia from older individuals (Hines et al., 1987). Hypothesis 5 expands the energy consumption life cycle theory to energy-saving behaviours. Regarding energy consumption, the life cycle theory identifies an inverted U-shape curve explained by an increased energy consumption through the child raising years, followed by a decline due to children leaving home (Fritzsche, 1981). An inverted U-shape has also been obtained by Hirst et al. (1982) concerning the relationship between the number of conservative behaviours and age, but this time caused by individual motivations and not households composition. When it comes to energy-saving behaviours, the explanation of the inverted U-curve is two-fold. The birth of children is a key feature in explaining the left hand side of the inverted U-shape, while individual aspirations are explaining the right hand side.

The impact of being a tenant is ambiguous as two opposite effects can be highlighted (Gillingham et al., 2012). Tenants live in less energyefficient houses as landlords tend to invest less to improve the performance of rented houses (Black et al., 1985; Barr et al., 2005), which induce energy-saving behaviours (Hypothesis 3 ). On the other hand, the financial impact of consuming energy is not always bear by the tenant as bills can be included in the renting price. This second effect would have a negative impact on the latent ability (Hypothesis 1). We find that the first effect dominates the second, this conclusion is driven from the fact that tenants impose to themselves more heating restrictions than owners. By going beyond the duality of the previous analysis, the positive impact of being tenant may also be related to a hidden revenue effect. In fact, 
for a same level of earnings an owner has generally more disposable income. Failing to prove Hypothesis 2, we can only speculate on the fact that this revenue effect is adding-up to the energyefficiency impact.

To explain the impacts of the heating system and living in a social housing, we need to look deeper in the correlation between these characteristics and individual energy behaviours. Households living in gas equipped housing modulate less their heating temperature ${ }^{8}$. This behaviour is surprising as modulating temperature seems easier with electrical heating equipment, but it explains the negative impact on energy behaviours. Households living in social housing tend to favour savings over comfort for heating, hot water and electricity consumption. It matches the fact that, once controlled by the revenue which is the main selection criterion, the decision of living in a social housing can be interpreted as a prime of saving upon comfort. In fact, living in this kind of dwelling enables to decrease the rent (Le Blanc and Laferrère, 2001).

Additionally, we note that being a male has a negative influence on behaviours but we need to stay cautious regarding the potential deductions from this result. In fact, this variable is an indication upon the gender of the individual declared as the reference person and gender is associated to a lot more intra-household volatility than previous variables. Unsurprisingly, the lowest equipment intensity goes with good energy-saving behaviours.

When comparing our results with Sardianou (2007), we find slightly different conclusions. While in line with Hypothesis 1 and Hypothesis 3, their conclusions support as well Hypothesis 2 and a neutrality of the education level. These differences lay within the fact that they chose to include in the definition of energy-saving behaviours (refer as energy conserving behaviours in their work) the attitude towards energy efficiency investments. As these investments are incentivised

\footnotetext{
${ }^{8}$ Concerning households using only electrical heating, $45 \%$ of them modulate heating temperature in the dwelling and $49 \%$ in the night space. For households using gas it goes up to, respectively, $50 \%$ and $55 \%$.
}

by a higher level of education or by higher financial resources, it explains the difference in conclusions. 


\begin{tabular}{|c|c|c|}
\hline & \multicolumn{2}{|c|}{ Latent Ability } \\
\hline & Coefficient & Variance \\
\hline Intercept & -0.448 & 0.773 \\
\hline \multicolumn{3}{|l|}{ Geographic area } \\
\hline Temperature index & $0.202^{* *}$ & 0.096 \\
\hline Rural commune & $-0.081^{*}$ & 0.040 \\
\hline \multicolumn{3}{|l|}{ Building } \\
\hline Isolated individual house & $0.117^{* *}$ & 0.057 \\
\hline Semi-detached house & $0.112^{* *}$ & 0.056 \\
\hline EPC: F-G & $0.067^{*}$ & 0.038 \\
\hline \multicolumn{3}{|l|}{ Indoor dwelling } \\
\hline Size & $-0.097^{*}$ & 0.051 \\
\hline Energy price & $0.139^{* * *}$ & 0.037 \\
\hline Shared central heating system & $-0.458^{* * *}$ & 0.086 \\
\hline Individual heating system & -0.051 & 0.048 \\
\hline Electrical heating system & $-0.090^{* *}$ & 0.042 \\
\hline Gas heating system & -0.065 & 0.044 \\
\hline Low equipment intensity & $-0.080^{*}$ & 0.043 \\
\hline High equipment intensity & $-0.109^{* *}$ & 0.048 \\
\hline Very high equipment intensity & $-0.095^{*}$ & 0.051 \\
\hline \multicolumn{3}{|l|}{ Individual } \\
\hline Earnings & -0.018 & 0.012 \\
\hline From 45 to 56 years old & $0.096^{* *}$ & 0.042 \\
\hline From 57 to 66 years old & 0.045 & 0.041 \\
\hline Tenant & $0.092^{*}$ & 0.049 \\
\hline Social housing & $0.131^{*}$ & 0.068 \\
\hline Farmer & 0.090 & 0.113 \\
\hline Employee & $0.116^{* *}$ & 0.050 \\
\hline Worker & $0.125^{* * *}$ & 0.046 \\
\hline Intermediate profession & $0.113^{* *}$ & 0.045 \\
\hline Employed & $-0.118^{*}$ & 0.060 \\
\hline Retired & -0.050 & 0.064 \\
\hline Male & $-0.069^{*}$ & 0.040 \\
\hline French & $-0.122^{* *}$ & 0.059 \\
\hline
\end{tabular}

Table 4: Multivariate regression of the latent abilities on the potential explaining factors selected by the adaptive lasso 


\section{Conclusion}

An extensive understanding of residential energy consumption is decisive to influence efficiently positive energy consumption patterns and measure accurately the potential effects on the climate. Analyses on energy consumption in residential buildings and debates regarding energy efficiency in the housing stock are dominated by physical and technical studies due to the complexity of the energy behaviours problematic and the lack of information on domestic energy usages. Statistical bottom-up studies focusing on determinant factors of household energy-saving behaviours are thus rather limited. The targeting of efforts towards the productive system and the technical attributes of the buildings is not sufficient to achieve a substantial reduction in domestic energy consumption. The lifestyles and behaviours of households leading to end-use energy consumption are also drivers of the evaluation and then foster energy efficiency. In this context, energy behaviours are a major missing element between the technological progress and the energy consumption.

This work explores the influencing factors of domestic energy-saving behaviours in France. The study is based on a detailed survey combining several information about dwelling attributes, occupant characteristics and behavioural variables. Starting with the idea that individual behaviours are not to be analysed without assessing the environment in which they are expressed, the PHEBUS survey has enabled us to evaluate the impact of a set of factors on energy-saving behaviours. This set is ranging from highly macro features such as the outdoor temperature to intrinsic micro individual characteristics, including exclusive information such as the EPC. Combining the IRT to quantitatively measure each household's ability to behave as energy-saver associated with the adaptive lasso method, we have highlighted five main vectors incentivising energy-saving behaviours based on cross-variable analysis. The identification of a positive price effect as well as a positive cost per unit of service effect are comforting expected tendencies, while the independence regarding revenue and especially the negative effect of education go upstream. The analysis of the inverted U-shape impact of the age on energysaving behaviours confirms the possible expansion of the energy consumption life cycle theory to energy-saving behaviours.

This research does not evaluate particular energy conservation policy but it suggests ways through which we can begin to think about how we value and integrate energy behaviours in the design of the future incentive energy policies to encourage energy-saving in the residential sector. The results should be useful to energy policymakers seeking to promote household energy efficiency and conservation to consider the importance of behavioural factors. Moreover, they enrich our understanding of energy behaviours' potential savings and suggest ways to develop new energy behaviours modelling strategies.

The use of micro level data can provide richer sources of information and opportunities to develop a deeper understanding of the factors affecting household energy-saving behaviours. In fact, the presented approach offers a new perspective to further researches which requires the collection and analysis of additional data. First of all, more detailed data on occupant behaviours and especially an observability of the behaviours in order not to be potentially victim of a report bias (Olsen, 1981) would strengthen the energy-saving behaviours evaluation. Regarding the potential factors of influence, information on the price $e x$ ante or a direct observation of the education level could be a first step potentially improving the strength of our results. A second one would be to analyse detailed information on all family members in a household to disentangle the direct effect of age linked to change in preferences from an indirect effect linked to the household composition. Finally information on households energy consumption before and after comprehensive thermal retrofits would enable to go from static analyses to dynamic ones and thus to obtain a direct measure of the rebound effect. 


\section{Appendix}

\section{Appendix A. Latent ability analysis}

\begin{tabular}{lccccc}
\hline \hline & Mean & St. Dev. & Min & Median & Max \\
\hline Latent ability & 0.023 & 0.724 & -1.163 & 0.012 & 1.573 \\
\hline
\end{tabular}

Table A.5: Statistical description of the latent ability

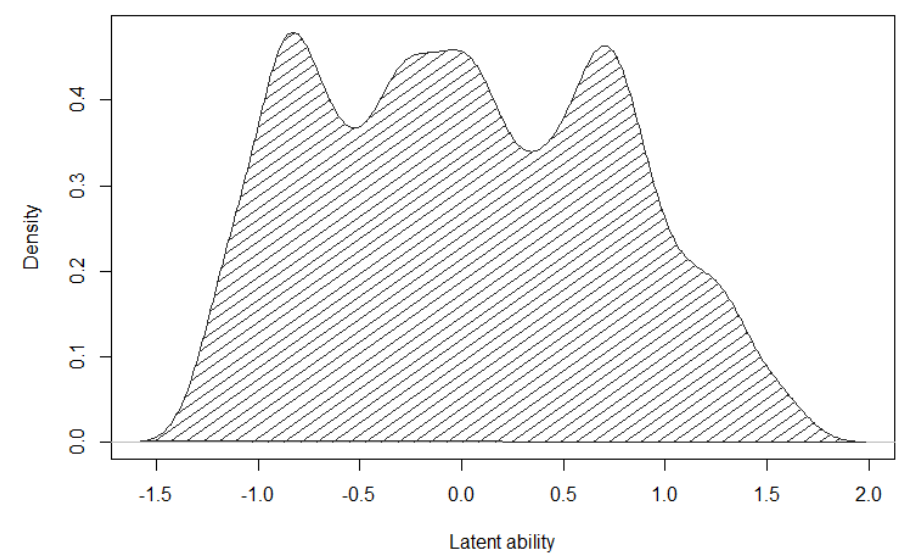

Figure A.4: Kernel density of the latent ability

\section{Appendix B. Adaptive lasso shrinkage pat- tern}

Figure B.5 presents the coefficient shrinkage using adaptive lasso after a 10-fold crossvalidation. In order to keep the appropriate variables, we have selected $\lambda$ as to minimise the mean cross-validated error. It is important to note that in the adaptive lasso, as well as in the lasso, factorial variables are considered as being independently evaluated enabling to keep only the relevant clusters for one characteristic. It explains the multitude of coefficients plotted which prevent us from displaying the associated variable for all of them. Only the name of the five last selected variables are indicated. The socio-professional categories worker and employee, the fact of being tenant and the energy prices having a positive effect on energy-saving behaviours while a shared heating system have the opposite effect.

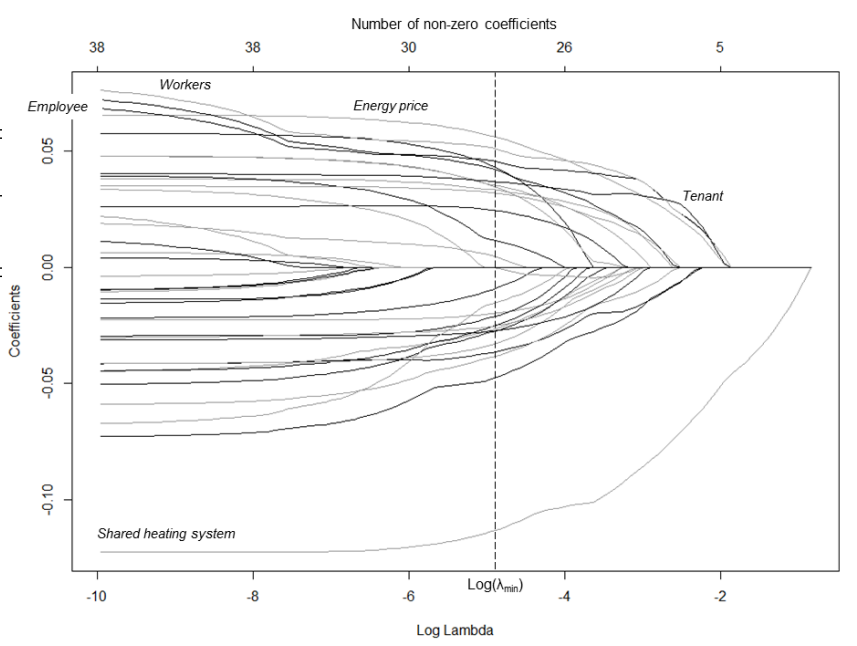

Figure B.5: Adaptive lasso shrinkage

\section{References}

Abrahamse, W., Steg, L., Vlek, C., and Rothengatter, T. (2005). A review of intervention studies aimed at household energy conservation. Journal of environmental psychology, 25(3):273-291.

Allcott, H. (2011). Social norms and energy conservation. Journal of Public Economics, 95(9):1082-1095.

Baker, F. B. and Kim, S.-H. (2004). Item response theory: Parameter estimation techniques. CRC Press.

Baker, P., Blundell, R., and Micklewright, J. (1989). Modelling household energy expenditures using micro-data. The Economic Journal, pages 720-738.

Barr, S., Gilg, A. W., and Ford, N. (2005). The household energy gap: examining the divide between habitual-and purchase-related conservation behaviours. Energy Policy, 33(11):1425-1444.

Berkhout, P. H., Muskens, J. C., and Velthuijsen, J. W. (2000). Defining the rebound effect. Energy policy, 28(6):425-432.

Bernard, J.-T., Bolduc, D., and Belanger, D. (1996). Quebec residential electricity demand: a microeconometric approach. Canadian Journal of Economics, pages 92 113.

Black, J. S., Stern, P. C., and Elworth, J. T. (1985). Personal and contextual influences on househould energy adaptations. Journal of applied psychology, 70(1):3.

Bourdieu, P. (1984). Distinction: A social critique of the judgement of taste. Harvard University Press.

Branch, E. R. (1993). Short run income elasticity of demand for residential electricity using consumer expenditure survey data. The Energy Journal, pages 111-121. 
Branco, G., Lachal, B., Gallinelli, P., and Weber, W. (2004). Predicted versus observed heat consumption of a low energy multifamily complex in switzerland based on long-term experimental data. Energy and Buildings, 36(6):543-555.

Breiman, L. (1995). Better subset regression using the nonnegative garrote. Technometrics, 37(4):373-384.

Brounen, D., Kok, N., and Quigley, J. M. (2012). Residential energy use and conservation: Economics and demographics. European Economic Review, 56(5):931945.

Caner, M. and Fan, M. (2011). A near minimax risk bound: adaptive lasso with heteroskedastic data in instrumental variable selection. Manuscript. North Carolina State University.

Cayla, J.-M., Allibe, B., and Laurent, M.-H. (2010). From practices to behaviors: Estimating the impact of household behavior on space heating energy consumption. In ACEEE Summer Study on Energy Efficiency in Buildings.

Cayla, J.-M., Maizi, N., and Marchand, C. (2011). The role of income in energy consumption behaviour: Evidence from french households data. Energy policy, $39(12): 7874-7883$.

Chwieduk, D. (2003). Towards sustainable-energy buildings. Applied energy, 76(1):211-217.

Darby, S. et al. (2006). The effectiveness of feedback on energy consumption. A Review for DEFRA of the Literature on Metering, Billing and direct Displays, 486:2006.

Dubin, J. A. and McFadden, D. L. (1984). An econometric analysis of residential electric appliance holdings and consumption. Econometrica: Journal of the Econometric Society, pages 345-362.

Dwyer, W. O., Leeming, F. C., Cobern, M. K., Porter, B. E., and Jackson, J. M. (1993). Critical review of behavioral interventions to preserve the environment research since 1980. Environment and behavior, 25(5):275-321.

Ehrhardt-Martinez, K., Donnelly, K. A., Laitner, S., et al. (2010). Advanced metering initiatives and residential feedback programs: a meta-review for household electricity-saving opportunities. American Council for an Energy-Efficient Economy Washington, DC.

Fabi, V., Andersen, R. V., Corgnati, S., and Olesen, B. W. (2012). Occupants' window opening behaviour: A literature review of factors influencing occupant behaviour and models. Building and Environment, 58:188-198.

Fan, J. and Li, R. (2001). Variable selection via nonconcave penalized likelihood and its oracle properties. Journal of the American statistical Association, 96(456):1348-1360.

Fan, J., Peng, H., et al. (2004). Nonconcave penalized likelihood with a diverging number of parameters. The Annals of Statistics, 32(3):928-961.

Fritzsche, D. J. (1981). An analysis of energy consumption patterns by stage of family life cycle. Journal of
Marketing Research, pages 227-232.

Gillingham, K., Harding, M., Rapson, D., et al. (2012). Split incentives in residential energy consumption. Energy Journal, 33(2):37-62.

Greening, L. A., Greene, D. L., and Difiglio, C. (2000). Energy efficiency and consumptionthe rebound effecta survey. Energy policy, 28(6):389-401.

Guerra-Santin, O. and Itard, L. (2010). Occupants' behaviour: determinants and effects on residential heating consumption. Building Research \& Information, $38(3): 318-338$.

Hines, J. M., Hungerford, H. R., and Tomera, A. N. (1987). Analysis and synthesis of research on responsible environmental behavior: A meta-analysis. The Journal of environmental education, 18(2):1-8.

Hirst, E., Goeltz, R., and Carney, J. (1982). Residential energy use: analysis of disaggregate data. Energy Economics, 4(2):74-82.

IEO (2013). International energy outlook. Technical report, U.S. Energy Information Administration.

Kaiser, F. G. (1998). A general measure of ecological behavior1. Journal of applied social psychology, 28(5):395422.

Labandeira, X., Labeaga Azcona, J. M., and Rodríguez Méndez, M. (2005). A residential energy demand system for spain. MIT Center for Energy and Environmental Policy Research Working Paper, (2005-001).

Le Blanc, D. and Laferrère, A. (2001). The effect of public social housing on households' consumption in france. Journal of Housing Economics, 10(4):429-455.

Lindén, A.-L., Carlsson-Kanyama, A., and Eriksson, B. (2006). Efficient and inefficient aspects of residential energy behaviour: What are the policy instruments for change? Energy policy, 34(14):1918-1927.

Lopes, M., Antunes, C., and Martins, N. (2012). Energy behaviours as promoters of energy efficiency: A 21st century review. Renewable and Sustainable Energy Reviews, 16(6):4095-4104.

Mizobuchi, K. and Takeuchi, K. (2013). The influences of financial and non-financial factors on energy-saving behaviour: A field experiment in japan. Energy Policy, 63:775-787.

Nesbakken, R. (2001). Energy consumption for space heating: a discrete-continuous approach. The Scandinavian Journal of Economics, 103(1):165-184.

Olsen, M. E. (1981). Consumers' attitudes toward energy conservation. Journal of Social Issues, 37(2):108-131.

Parti, M. and Parti, C. (1980). The total and appliancespecific conditional demand for electricity in the household sector. The Bell Journal of Economics, pages 309321 .

Pickett, G. M., Kangun, N., and Grove, S. J. (1993). Is there a general conserving consumer? a public policy concern. Journal of Public Policy \& Marketing, pages $234-243$ 
Risch, A. and Salmon, C. (2013). What matters in residential energy consumption? evidence from france.

Samejima, F. (1969). Estimation of latent ability using a response pattern of graded scores. Psychometrika monograph supplement.

Sanquist, T. F., Orr, H., Shui, B., and Bittner, A. C. (2012). Lifestyle factors in us residential electricity consumption. Energy Policy, 42:354-364.

Sardianou, E. (2007). Estimating energy conservation patterns of greek households. Energy Policy, 35(7):37783791.

Sonderegger, R. C. (1978). Movers and stayers: the resident's contribution to variation across houses in energy consumption for space heating. Energy and Buildings, 1(3):313-324.

Steg, L. and Vlek, C. (2009). Encouraging proenvironmental behaviour: An integrative review and research agenda. Journal of environmental psychology, 29(3):309-317.

Summerfield, A. J., Pathan, A., Lowe, R. J., and Oreszczyn, T. (2010). Changes in energy demand from low-energy homes. Building Research $\&$ Information, $38(1): 42-49$.

Swan, L. G. and Ugursal, V. I. (2009). Modeling of end-use energy consumption in the residential sector: A review of modeling techniques. Renewable and sustainable energy reviews, 13(8):1819-1835.

Tibshirani, R. (1996). Regression shrinkage and selection via the lasso. Journal of the Royal Statistical Society. Series B (Methodological), pages 267-288.

Valenzuela, C., Valencia, A., White, S., Jordan, J. A., Cano, S., Keating, J., Nagorski, J., and Potter, L. B. (2014). An analysis of monthly household energy consumption among single-family residences in texas, 2010. Energy Policy, 69:263-272.

Yue, T., Long, R., and Chen, H. (2013). Factors influencing energy-saving behavior of urban households in jiangsu province. Energy Policy, 62:665-675.

Zhou, S. and Teng, F. (2013). Estimation of urban residential electricity demand in china using household survey data. Energy Policy, 61:394-402.

Zou, H. (2006). The adaptive lasso and its oracle properties. Journal of the American statistical association, 101(476):1418-1429. 